\title{
Lean thinking to mind the gap in healthcare management
}

\author{
Pensamento enxuto na gestão da saúde
}

We congratulate your team for your initiative to improve healthcare delivery to stroke patients ${ }^{1}$. The participation of multidisciplinary staff working at Gemba (where the work is done) is an excellent approach, discussing the strengths and weaknesses of care delivery, anticipating threats and looking for opportunities. We agree entirely with your views on quick-fixes, which may create work-arounds that do not address underlying issues. It is like prescribing a medication without a clear diagnosis or understanding of the problem. Healthcare management is strategic; in many areas of healthcare delivery, treatment efficacy and also safety take place outside the boundaries of pharmakinetics or procedures. Stroke patients are a good example. We know about rt-PA as a hyperacute ischaemic treatment, but in order for the medication to work safely, we engage in looking into each patient's 5 R's (right medication, right dose, right time, right route, right patient). In the United States, it has been estimated that over 98 thousand patients per year have died of medical errors². One way to reduce this toll is to start with education about management and quality improvement, which is neglected in the Medicine curriculum. We need to mind the gap, and to move from intuitive "gut feelings", to a logical, data-driven, stance in healthcare management. Lean thinking, derived from Toyota's Production System, has been adopted in many healthcare setting with success. Lean thinking is not a set of tools, but is rather a more philosophical approach towards management, founded on the concepts of relentless elimination of waste and continuous improvement. For example, eight broad types of waste have been identified, often summarized with the acronym DOWNTIME: Defect (give a wrong medication), Overproduction (ask for exams that are not needed), Waiting (a patient waiting for consultation, a surgical team waiting for an operating room), No use of staff (not listening to employee's suggestions), Transportation (patients need to go to several places), Inventory (expired medication), Motion (employee walks to distant areas to get supply), and Extra processing (generate duplicate documents). The Institute of Healthcare Improvement has developed a tool ${ }^{3}$ to help in identifying wastes in a hospital. Your group is on the Lean journey, not wasting the collective intelligence and looking to improve your work. We believe this effort is worthwhile, as it can provide more efficient and safer care for your patients as well as an improved work environment for your staff.

Li Min $\mathrm{Li}^{1,2,3}$, Sharon Johnson ${ }^{1}$

\section{References}

1. Spagnol GS, Valler L, Avellar WM. Improvement initiative in stroke care. Arq Neuropsiquiatr; 2015;73(11):978. doi:10.1590/0004-282X20150144

2. Donaldson MS. An overview of to err is human: re-emphasizing the message of patient safety. In: Hughes, RG, editor. Patient safety and quality: an evidence-based for nurses. Rockville: Agency for Healthcare Research and Quality; 2008. Chapter 3.

3. Resar RK, Griffin FA, Kabcenell A, Bone C. Hospital inpatient waste identification tool. Cambridge: Institute for Healthcare Improvement, Massachusetts; 2011.

\footnotetext{
${ }^{1}$ Robert A. Foisie School of Business, Healthcare Delivery Institute, Worcester Polytechnic Institute, Worcester MA, USA;

¿UMass Medical School, Worcester MA, USA;

${ }^{3}$ Universidade Estadual de Campinas, Faculdade de Ciências Médicas, Departamento de Neurologia, Campinas SP, Brazil.

Correspondence: Li Li Min; Foisie School of Business, Washburn Shops 215, 100 Institute Road; 01609 Worcester MA, USA; E-mail: limin@fcm.unicamp.br

Conflict of interest: There is no conflict of interest to declare.

Support: Li Li Min is recipient of FAPESP Scholarship 2014/10911-3.

Received 28 July 015; Accepted 17 August 2015.
} 